\title{
A FLAGRANTE INCOMPATIBILIDADE ENTRE O INSTITUTO DA ASSISTÊNCIA À ACUSAÇÃO E A CONSTITUIÇÃO FEDERAL DE 1988
}

\begin{abstract}
Aline Adams ${ }^{1}$
Resumo: O instituto da assistência à acusação, previsto no Código de Processo Penal de 1941 era considerado um órgão auxiliar ao Ministério Público na promoção das ações penais públicas., até 1988 quando a Constituição Federal consagrou tal dever como função privativa do parquet. A par disso, a assistência à acusação continua ocupando lugar de destaque em nossos tribunais, muito embora seja flagrante a sua não-recepção pela Carta Magna e a sua violação ao Estado Democrático de Direitos.
\end{abstract}

Palavras-chave: Processo Penal. Assistência à acusação. Constituição Federal de 1988.

\begin{abstract}
The institute of prosecution assistance, predicted in the Penal Process Code of 1941, was considered an auxiliary organ in the promotion of the public penal actions, until the Federal Constitution of 1988 considered such duty as a privative function of the parquet. In the other hand, the prosecution assistance keeps holding a prominent position in our tribunals, although it is flagrant its non-reception by the Magna Letter and its violation to the Democratic State of Right.
\end{abstract}

Key-Words: Penal Process. Prosecution Assistance. Federal Constitution of 1988.

\section{CONSIDERAÇÕES INICIAIS}

É sabido que a Constituição Federal de 1988 consagrou no seu artigo 129, I, como função privativa do Ministério Público a promoção da ação penal pública. No entanto, o Código de Processo Penal de 1941 traz o instituto da assistência à acusação, com um auxiliar do órgão ministerial nas ações penais públicas.

Assim, urge discutir o instituto da assistência à acusação frente à ordem constitucional vigente e o Estado Democrático de Direitos.

\section{Instituto da assistência à acusação e o código de processo penal de 1941: do retorno à vingança privada}

\footnotetext{
${ }^{1}$ Bacharela em Direito pela Universidade Federal de Santa Maria, especialista em Ciências Penais pela PUCRS, mestranda em Ciências Criminais pela PUCRS e advogada. Email alineadams_sm@hotmail.com.

(C) 2008. Departamento de Direito da UFSM. Todos os direitos reservados.
} 
Cumpre analisar especificamente a assistência à acusação no que diz respeito a sua inserção no Código de Processo Penal de 1941. Seguindo o momento histórico vivido na década de 40 - o fascismo - o referido Código elencou em seu artigo 268 a figura do assistente à acusação. Em tal norma há a possibilidade de que "em todos os termos da ação pública poderá intervir, como assistente do Ministério Público, o ofendido ou seu representante legal, ou, na falta, qualquer das pessoas mencionadas no art. 31".

Segundo ZIYADE (1993, p. 32), uma das possíveis origens brasileiras do instituto é o Código de Processo Penal do Rio Grande do Sul de 1898 que em seu artigo $7^{\circ}$ dispunha:

Em todos os termos da ação privada será sempre ouvido o Ministério Público; e nos da ação pública pode intervir a parte ofendida ou quem a substitua para defender seu direito como assistente.

Parágrafo único: $O$ assistente pode intervir antes ou depois da sentença, contando que esta não tenha passado em julgado, mas recebe a causa do estado em que se acha e deve alegar seu direito nos termos que competem ao Ministério Público.

Entretanto, já o Código Penal de 1890, no artigo 408 autorizava a participação da vítima nos "processos iniciados por denúncia, ou por ato ex officio, para auxiliar a acusação". Assim, considerando a característica absolutamente processual da norma, o Supremo Tribunal Federal determinou na época, em sede de hábeas corpus, que a competência para legislar acerca da matéria (precisamente no que consistia efetivamente o auxílio previsto pela Lei Federal), consoante disposição constitucional, era dos estadosmembros. Desta feita, de acordo com Fernandes (1995, p. 32) os códigos de vários estados expressamente passaram a dispor do assunto, como por exemplo do Rio de Janeiro, Minas Gerais e do Distrito Federal.

Insta salientar, portanto, que o momento histórico verificado no texto atual do código de processo penal é datado do período do Estado Novo, impulsionado pelo combate ao comunismo e pelas idéias fascistas. A Constituição vigente era a de 1937, a qual introduziu no país a possibilidade da pena de morte $^{2}$ e da censura ${ }^{3}$, não experimentadas

\footnotetext{
${ }^{2}$ A pena de morte inserida na Constituição de 1937 era prevista para os seguintes crimes: a) tentar submeter o território da Nação ou parte dele à soberania de Estado estrangeiro; b) tentar, com auxilio ou subsidio de

(C) 2008. Departamento de Direito da UFSM. Todos os direitos reservados.
} 
anteriormente por outras cartas constitucionais. Assim, "em 1937, temos um modelo de Constituição autoritário, mantendo direitos sociais e econômicos dentro de uma perspectiva intervencionista, inibindo instrumentos de manifestação coletiva".(DORELLA, 1997.)

Ora, considerando que o estado vigente era o fascista, é lógico concluir que, ao tempo da feitura do Código de Processo Penal, o instituto da assistência à acusação encontrava amparo jurídico e constitucional. Entretanto, sob a égide de um Estado Democrático de Direitos não se pode permitir que haja a "ampla acusação" - por parte do Ministério Público e da vítima - em oposição à "ampla defesa" - na maioria das vezes realizada pela Defensoria Pública, mal aparelhada e carente de recursos materiais e pessoais.

E esta tal vítima que pode exercer a assistência à acusação possuiu basicamente três papéis na história do direito processual penal: o primeiro ainda na fase da vingança privada, passando posteriormente para o período inquisitivo, no qual a punição do culpado era um dever sagrado exercido pelo Estado conjuntamente com a Igreja e a fase atual em que a tutela penal é de exclusividade estatal.

Durante o período da vingança privada, ocorrendo um crime logo se dava a vingança da vítima, dos parentes e até da tribo a qual pertencia, não havendo limites para a resposta à agressão. Deve ser considerado apenas uma realidade sociológica e não um instituto jurídico, vez que não precedia de qualquer regramento, sendo uma reação natural e instintiva. (DUARTE, 1999)

Assim, na chamada fase da vingança privada

poderia envolver desde o indivíduo isoladamente até o seu grupo social, com sangrentas batalhas, causando, muitas vezes, a completa eliminação do grupo. Quando a infração fosse cometida por membro do próprio grupo, a punição era o banimento (perda da paz), deixando-o à mercê de outros grupos, que fatalmente o

Estado estrangeiro ou organização de caráter internacional, contra a unidade da Nação, procurando desmembrar o território sujeito à sua soberania; c) tentar por meio de movimento armado o desmembramento do território nacional, desde que para reprimi-lo se torne necessário proceder a operações de guerra; d) tentar, com auxilio ou subsidio de Estado estrangeiro ou organização de caráter internacional, a mudança da ordem política ou social estabelecida na Constituição; e) tentar subverter por meios violentos a ordem política e social, com o fim de apoderar-se do Estado para o estabelecimento da ditadura de uma classe social; f) o homicídio cometido por motivo fútil e com extremos de perversidade;

${ }^{3}$ A censura prevista no Estado Novo, tinha como fim garantir a paz, a ordem e a segurança pública (art. 15 da Constituição de 1937). Determinava que a autoridade competente podia proibir a circulação, a difusão ou a representação de material de imprensa ou de teatro, cinema e radiodifusão. 
levariam à morte. Quando, no entanto, a violação fosse praticada por alguém estranho ao grupo, a punição era a "vingança de sangue", verdadeira guerra grupal (BITENCOURT, 2002, p. 21).

Posteriormente, com o fim de evitar a dizimação das tribos, surgiu a Lei de Talião, postulando pela reação proporcional ao mal praticado, ou seja, "olho por olho, dente por dente", tendo sido adotada no código Hamurabi (Babilônia), no Êxodo (hebreus) e na Lei das XII Tábuas, em Roma (FRAGOSO, 1985, p. 26 apud BITENCOURT, 2002, p. 22). Com o passar dos tempos, surge a composição, sistema no qual o acusado comprava a sua liberdade com dinheiro, armas, gado, etc.Tal instituto deu origem às indenizações civis e às penas pecuniárias do Direito Penal.

Já a fase da vingança divina tem como ofendido principal os deuses e, por isso, o que predomina é a satisfação da divindade. Pune-se com maior rigor e crueldade, sendo os sacerdotes os agentes responsáveis por esta punição (CAPELA, 2002).

No período da vingança pública, os deuses deixam de ser o verdadeiro centro das atenções passando esta para o monarca (rei, príncipe, regente). Com a evolução social, portanto, o Estado passou a afastar a vingança privada, assumindo para si a tutela da ordem e da segurança. (BITENCOURT, 2002, p. 22)

Baseado nas idéias iluministas e no Contrato Social, Beccaria publicou em 1764 a obra "Dos delitos e das penas", buscando construir um novo sistema penal, substituindo o desumano e cruel anterior. Nesse viés, tinha uma concepção utilitarista da pena. "Procurava um exemplo para o futuro, mas não uma vingança pelo passado, celebrizando a máxima de que 'é melhor prevenir delitos que castiga-los"”.(BITENCOURT, 2002, p. 22)

Um dos fortes argumentos pela manutenção do instituto da assistência à acusação (e também pelo seu alargamento às hipóteses não contempladas pela legislação, como da vítima recorrer apenas para agravar a pena) é inicialmente em virtude de que uma decisão transitada em julgado na esfera penal permite a execução ex delicto na seara cível. Permitese, portanto, que a o ofendido busque indenização civil se já houver transitado em julgada a decisão condenatória penal. No entanto, "o ofendido terá a oportunidade de executar a ação penal condenatória, podendo, se preferir, discutir o mérito de sua pretensão, 
ingressar no juízo cível, inclusive com maior amplitude, sabido que a culpa cível é bem mais abrangente do que a penal." (STRECK, 2001, p. 159)

Além disso, entendem alguns doutrinadores que outro interesse do assistente à acusação seria a 'justa condenação' criminal. O assistente, portanto,

não se limita apenas à busca de subsídios para a realização dos consectários indenizatórios determinados pelo delito, nem ele se amostra como auxiliar passivo do assistido, o Ministério Público. Resta patente que sua ingerência processual, nos termos do que é autorizado pela lei, proporciona-lhe o poder de ir em busca da realização da justica plena, consoante concebida por ele em nome de seus interesses (...) (PATENTE, 2003. p. 27), (grifos)

A busca, contudo, não se esvai na 'justiça plena', mas também na chamada verdade real dos fatos. Senão vejamos o seguinte acórdão do Superior Tribunal de Justiça:

O processo penal é complexo de relações jurídicas que tem por objeto a aplicação da lei penal. Não há partes, pedido ou lide, nos termos empregados no processo civil. Juridicamente, acusação e defesa conjugam esforços, decorrência do contraditório e defesa ampla, para esclarecimento da verdade real. Ninguém pode ser condenado sem o devido processo legal. O assistente também é interessado na averiguação da verdade substancial. $O$ interesse não se restringe à aquisição de título executório para reparação de perdas e danos. $O$ direito de recorrer, não o fazendo o Ministério Público, se dá quando a sentença absolveu o réu, ou postulando aumento de pena. A hipótese não se confunde com a justica privada. A vítima como o réu tem direito à decisão justa. A pena, por seu turno, é a medida jurídica do dano social decorrente do crime.(PATENTE, 2003, p. 28)

Esclareça-se, muito embora em linhas gerais, que a famigerada 'verdade real' não passa de um mito. Para isso, basta compreender o pleonasmo existente na expressão. Não pode existir verdade que não seja real, pois sendo um fato verdadeiro, deve necessariamente ser real, não havendo, logo, verdades irreais. Assim, se não há verdades irreais, conclui-se que toda verdade é real! O problema, então, situa-se somente na questão da 'verdade' e não mais na 'verdade real'.

Não se trata de construir, mas de reconstruir um fato passado no presente. Ora, basta isso para afirmar que não existe um dado de realidade para falar em verdade (muito menos real). É o absurdo de equiparar o real ao imaginário, esquecendo que o passado só existe no imaginário, na memória, e que, por isso,

(C) 2008. Departamento de Direito da UFSM. Todos os direitos reservados. 
jamais será real, sem falar que a flecha do tempo é irreversível, de modo que o que foi real, num fugaz presente, jamais voltará a sê-lo. (LOPES Jr. 2006, p. 216)

Na esteira de Carnelutti, a verdade é o todo que jamais será alcançado pelo homem, devendo ser abandonada, portanto, a noção 'verdade'. A questão deixa de ser, assim, a tal 'verdade real' e passa a ser apenas a inexistente 'verdade'. Afinal, um fato passado jamais poderá ser recuperado por completo, ainda que apenas na memória.

Com razão CARNELUTTI quando dizia (já em 1925) ser estéril a discussão a respeito de viger a verdade real (material) ou a verdade processual (formal). $O$ problema é a "verdade". Para o autor, inspirado em HEIDEGGER, a verdade é inalcançável, até porque a verdade está no todo, não na parte; e o todo é demais para nós. Além de inalcançável, tampouco existem verdades absolutas, como a própria ciência encarregou-se de demonstrar, pois todo o saber é datada e tem prazo de validade (Einsten). Uma teoria só vale até que outra venha para negá-la. Logo, a verdade está no todo e o todo é excessivo, jamais pode ser alcançado pelo homem (LOPES Jr. 2006, p. 278)

Salientam alguns autores de entendimento mais tradicional que, considerando a 'clientela' do direito penal, basicamente formada de pessoas muito pobres ou miseráveis, que jamais terão condições de arcar com indenizações civis pelo ilícito cometido, pelo menos haverá justa reprimenda penal. "E, se a prática vem denotando a impossibilidade de as vítimas exercerem seu direito ao ressarcimento dos prejuízos sofridos, injusto seria impedir-lhes o direito à obtenção de decisões justas, o que também significa a busca do equilíbrio social e moral." (grifos) (ALMEIDA, 2002)

Entretanto, como bem assevera Ferrajoli, o princípio axiológico da separação entre direito e moral proíbe que comportamentos meramente imorais ou de estado de ânimo pervertidos, hostis ou, até mesmo, perigosos sejam vetados pelo Estado (2006, p. 234). Portanto, devendo haver distinção entre moral e direito, absolutamente descabido o argumento de que é direito do ofendido uma decisão que busque o equilíbrio social e moral. Aliás, não é demais referir que a questão "moral" advém de conceitos antropológicos de cultura e, como tal, é diferente entre as pessoas.

Considerando, então, que todo saber é datado, se pode mais amplamente determinar que toda legislação (assim como toda produção literária) deve ser analisada diante do quadro histórico em que foi produzida. Desta feita, o código de processo penal 
quando traz a assistência a acusação, como auxiliar do órgão ministerial na tarefa de exercer a busca pelo ius puniendi, deve ser interpretado de acordo com momento vivido em 1941 - e conseqüentemente com a Constituição vigente à época, sob pena de retroceder na evolução social, alimentando a idéia de vingança por parte da vítima.

\section{A assistência à acusação e a sua não-recepção pela Constituição Federal de 1988.}

O legislador constituinte, ao dispor no artigo 129, I que uma das funções institucionais do Ministério Público é "promover, privativamente, a ação penal pública na forma da lei" excluiu a ação penal pública ex officio, iniciada por portaria judicial ou de autoridade policial e através de prisão em flagrante. Desta feita, sendo constitucionalmente o órgão ministerial o "dono da ação penal", evidente estar derrogado o Código de Processo Penal no que diz respeito ao assistente à acusação.

Nesse sentido, cumpre referir que a Constituição positivada é o documento que reflete os valores políticos do corpo social que o desenvolveu (GERBER, 2005). Assim, é necessária a existência de legitimidade formal e material, consubstanciada, esta última, nos valores elevados ao patamar de 'fundamentais'.

(...) A constituição é um conjunto de regras jurídicas de valor proeminente porque estas são portadoras de determinados conteúdos aos quais é atribuído numa comunidade um 'valor especifico superior. Como se vê, a constituição normativa, para se qualificar como um conceito de 'dever ser', ou, por outras palavras, para ser qualificada como conceito de valor, não se basta com um conjunto de regras jurídicas formalmente superiores; estas regras têm de transportar 'momentos axiológicos'corporizados em normas e princípios dotados de bondade material (garantia de direitos e liberdades, separação de poderes, controlo do poder, governo representativo) (CANOTILHO, 2004, p. 1095)

O artigo 129, I, da Constituição Federal, ao determinar que apenas o Ministério Público tem interesse e legitimidade para promover a ação penal pública outra coisa não fez senão alterar a ordem vigente e, assim o fazendo, não-recepcionar nenhum dispositivo contrário a essa nova determinação.

Sinale-se que a não-recepção de uma norma infraconstitucional pela nova Carta Política se dá quando aquela for incompatível com os preceitos trazidos por esta. Como é

(C) 2008. Departamento de Direito da UFSM. Todos os direitos reservados. 
sabido, após o julgamento da ADIn n. 2 pelo Supremo Tribunal Federal, firmou-se posicionamento no sentido de que havendo incompatibilidade entre norma infraconstitucional com Constituição promulgada posteriormente, ocorre o fenômeno da revogação implícita, ou inconstitucionalidade superveniente, como tratado pela doutrina.

Sabemos que pelo fenômeno da recepção, a Constituição nova recebe a ordem normativa que surgiu sob o império de Constituições anteriores se com ela forem compatíveis, no dizer de Michel Temer, assim, toda a normatividade infraconstitucional terá como parâmetro a nova Constituição, subsistindo no ordenamento somente as normas que forem compatíveis com esta. (TEMER, 1992 apud OLIVEIRA, 2003)

Sendo assim, havendo flagrante desrespeito da norma infraconstitucional com a Constituição Federal, notório estar derrogado o Código de Processo Penal quando trata do instituto da assistência à acusação.

Insta referir que o assistente à acusação se harmoniza perfeitamente com um modelo de estado liberal-individualista, de cunho ordenador, ao passo que num Estado Democrático de Direitos a defesa do direito individual dá lugar à dos direitos sociais e coletivos.

Nesse sentido, sendo o Ministério Público um órgão estatal independente e sem vinculação com o ofendido, cujo papel principal é a fiscalização legal, totalmente descabida a figura do assistente à acusação. Veja-se tal mais explicitamente quando o promotor de justiça, analisando a prova de forma técnica, requer a absolvição no Tribunal do Júri, enquanto o assistente, respondendo aos anseios da vítima ou de sua família (e até mesmo demonstrando o valor empregado nos honorários advocatícios) utiliza-se basicamente da retórica.

Certamente, a jurisprudência nacional, ainda relutante, saberá expurgar do sistema jurídico brasileiro a figura do assistente de acusação, eis que seu malefício destaca-se no Tribunal do Júri, onde, até mesmo em constrangedora colisão como pensamento do Ministério Público, sua atuação, patrocinada pela família da vítima, obriga-o a acusar, numa estranha e triste similitude com o princípio da obrigatoriedade defensiva, gerando lamentável perplexidade no Conselho de Defesa.(NASSIF, 1996, p. 101) 
Ora, se o próprio "dono da ação" desiste de seu pleito acusatório, requerendo a absolvição do réu, não pode a assistência invocar a condenação, sob pena de regresso à vingança privada, à confusão entre direito e moral, ao fascismo e ao Estado social mínimo.

Ademais, o instituto em tela apenas reforça a medieval idéia de direito penal do autor, quando na realidade o direito penal deve ser analisado sob a ótica do fato.

O Tribunal e Justiça do Rio Grande do Sul já vem decidindo em algumas de suas câmaras nessa linha de raciocínio. Senão vejamos:

EMBARGOS INFRINGENTES. CONFORMIDADE DO MINISTÉRIO PÚBLICO COM A SENTENÇA CONDENATÓRIA DE PRIMEIRO GRAU. APELO DO ASSISTENTE DE ACUSAÇÃO. ILEGITIMIDADE POSTULATÓRIA. AUSÊNCIA DE INTERESSE PÚBLICO. INCONSTITUCIONALIDADE.

- O elemento que distingue os ilícitos penais dos civis é a irreparabilidade do dano, ou seja, o interesse público que reside na parcela de lesão que a indenização/reparação cível não consegue confortar.

- O Direito Penal, enquanto ramo do Direito Público, não pode permitir que a vítima consagre seus interesses privados através da estrutura estatal-judiciária penal.

- A participação da vítima no processo penal - com "P" maiúsculo (sentido forte que a expressão ao menos deveria ter) - reforça as doutrinas retributivas cuja máxima de justiça é a devolução do mal com o mal - "venganza de la sangre", diria Ferrajoli.

- O Estado de Direito, enquanto negação da vingança privada, implanta o fim da dominação do mais forte, tomando para si o monopólio do direito de punir.

- A Constituição Federal admite a intervenção da vítima no processo penal, através da ação penal privada subsidiária da pública (art. $5^{\circ}, \mathrm{LIX}$, da CF), nos casos de inércia do órgão ministerial. Contrario sensu, havendo movimentação do Ministério Público, porém em direção contrária ao interesse da vítima, cuida-se de conflito de interesses (público e privado), e não de omissão do parquet, hipótese diferenciada da exceção constitucional à acusatoriedade pública.

- Por maioria, acolheram os embargos" (Embargos Infringentes 70005315270, $3^{\circ}$ Grupo Criminal, TJRS, Rel. Amilton Bueno de Carvalho, j. em 21.03.03).

ASSISTENTE DE ACUSAÇÃO. Frente a disposição nas matérias do art. 109, inc. I, da Constituição Federal, é de ser reconhecida a ausência do assistente de acusação para recorrer por falta de legitimidade. Prescrição e medida de segurança. Atende ao principio de isonomia reconhecer a pena-base mínima como prazo para a presunção de mandado de segurança. Recurso do assistente de acusação não conhecido. Declarada extinta a punibilidade de Luciano (...) pela prescrição. (APELAÇÃO CRIME N. ${ }^{\circ}$ 70005150453, QUINTA CÂMARA CRIMINAL, TRIBUNAL DE JUSTIÇA DO RS, RELATORA: GENACÉIA DA SILVA ALBERTON, JULGADO EM 25/06/2003)

(C) 2008. Departamento de Direito da UFSM. Todos os direitos reservados. 


\section{PROCESSUAL PENAL. APELO DO ASSISTENTE DE ACUSAÇÃO. ILEGITIMIDADE POSTULATÓRIA. AUSÊNCIA DE INTERESSE PÚBLICO. INCONSTITUCIONALIDADE.}

1. Com a superação da vingança privada, o Estado, como reserva ética, assume a condição de "ofendido" e cala a vítima. Trata-se de conquista da civilização porque o punir assume sua condição de racionalidade, afastando as ambições menos nobres daquele que sofre o crime diretamente, via de regra permeadas pela emotividade e pelo sentimento de busca de punição a qualquer preço.

2. O Direito Penal, enquanto ramo do Direito Público, não comporta a participação da vítima para a busca da consagração de seus interesses privados (recomposição dos danos sofridos) que, por certo, são merecedores da proteção do Estado, mas no local próprio, qual seja, o juízo cível.

3. A Constituição Federal admite a intervenção da vítima no processo penal somente através da ação penal privada subsidiária da pública (art. $5^{\circ}$, LIX, da $C F)$, nos casos de inércia do órgão ministerial - única exceção prevista à acusatoriedade exclusivamente pública -, hipótese diversa da retratada nestes autos.

Não conheceram do apelo. UNÂNIME. (APELAÇÃO CRIME No 70013178421, QUINTA CÂMARA CRIMINAL, TRIBUNAL DE JUSTIÇA DO RIO GRANDE DO SUL, RELATOR: AMILTON BUENO DE CARVALHO, JULGADO EM 30/11/2005).

\section{RECURSO DO ASSISTENTE DE ACUSAÇÃO. ILEGITIMIDADE POSTULATÓRIA. AUSÊNCIA DE INTERESSE PÚBLICO.} INCONSTITUCIONALIDADE.

O Direito Penal, enquanto ramo do Direito Público, não pode permitir que a vítima consagre seus interesses privados através da estrutura estatal-judiciária penal. A Constituição Federal admite a intervenção da vítima no processo penal unicamente através da ação penal privada subsidiária da pública (art. $5^{\circ}, \mathrm{LIX}$, da CF), nos casos de inércia do órgão ministerial. Contrario sensu, havendo movimentação do Ministério Público, porém em direção contrária ao interesse da vítima, tem-se por não configurada da exceção constitucional à acusatoriedade pública.

Recurso não conhecido. UNÂNIME. (Recurso em Sentido Estrito, Quinta Câmara Criminal, $N^{o}$ 70015840002, Relator Amilton Bueno de Carvalho, julgado em 16.08.2006).

Refere-se, por fim, que diante da inércia ministerial, há a possibilidade constitucional, elencada inclusive como direito fundamental (artigo $5^{\circ}$, LIX), da vítima oferecer a denúncia - é a chamada ação penal privada subsidiária da pública. Entretanto, em que pese ser norma constitucional originária, entende-se que não é a melhor lógica. Isto porque, considerando que o direito penal é público e a vítima tem interesse apenas privado, o meio mais eficaz de provocar o dito parquet a oferecer a denúncia, em caso de não ter 
sido a mesma intentada no prazo legal, é a imposição da sanção estabelecida no artigo 801 do Código de Processo Penal ${ }^{4}$. Assim,

Quanto a ação penal privada subsidiária, sempre tive, de fato, como extravagante e mal inspirado expediente de indébita intervenção particular em assuntos da alçada pública. Sem falar naquele outro inconveniente, igualmente sério, da incompatibilidade indefectivelmente estabelecida, nos processos assim iniciados, entre o ofendido e o acusador público a seguir interveniente (art. 29, segunda parte, do CPP vigente). O recurso à hierarquia, com a designação, diante da só evidência do atraso no oferecimento da denúncia, de outro membro do Ministério Público para oficiar, sobre se apresentar como lógica solução para problema manifestado em quadro funcional de estrutura organizada, oferecida a vantagem de prevenir atritos como o retrodestacado. (...) É certo, outrossim, que, no plano hierárquico, comprovada a relapsia do representante do Ministério Público, ficaria o mesmo sujeito às sanções de direito ordinariamente previstas nas bases institucionais da carreira. De minha parte, bem de ver, como meio eficaz de combate à desídia ministerial, advogo a mantença da punição prevista no artigo 801 do CPP. Verificado o atraso, injustificável, decretariam tais sanções os escalões hierárquicos (MELLO, p. 207-213 apud NUCCI, 2006, p. 138/139).

\section{CONSIDERAÇÕES FINAIS}

O Código de Processo Penal reflete em vários de seus artigos o caráter fascista do tempo de sua formulação. A constituição vigente na época era absolutamente rígida e conservadora, permitindo, portanto, a inserção de normas desse cunho. No entanto, com o advento do Estado Democrático de Direitos, através da Constituição de 1988, muitos dos artigos do CPP não foram recepcionados. Entre eles, está o instituto da assistência à acusação.

Enquanto ramo do direito público, o direito penal não pode consagrar meios privados para que a vítima defenda seus interesses. Para isso existe a esfera cível, cuja amplitude é alargada em relação à seara penal. Possibilitar ao ofendido reação penal nada mais é que um retrocesso à vingança privada. Isto porque, o Estado, ao assumir para si os meus de exercer o ius puniendi retirou do cidadão essa condição, afastando qualquer ambição movida pela emoção e pela busca desmedida de punição.

\footnotetext{
${ }^{4}$ Art. 801 Findos os respectivos prazos, os juízes e os órgãos do Ministério Público, responsáveis pelo retardamento, perderão tantos dias de vencimentos quantos forem os excedidos. Na contagem do tempo de serviço, para o efeito de promoção e aposentadoria, a perda será do dobro dos dias excedidos.

(C) 2008. Departamento de Direito da UFSM. Todos os direitos reservados.
} 
É sabido que o Ministério Público, por ser imparcial, é o órgão constitucionalmente incumbido de promover a ação penal pública e apenas em caso de sua inércia é que é permitido pela $\mathrm{CF} / 88$ o oferecimento da denúncia por parte da vítima. No entanto, até mesmo esse artigo, em que pese estar incluído no rol dos direitos fundamentais, pode ser discutido, considerando as sanções previstas no artigo 801 do CPP.

Desta feita, sob pena de retorno ao estado social mínimo e ao fascismo, deve deixar de ser aplicado o instituto da assistência à acusação, pela sua evidente não-recepção pela Constituição Federal de 1988.

\section{REFERÊNCIAS BIBLIOGRÁFICAS}

ALMEIDA, José Maurício Pinto de. Recurso de apelação-crime pelo assistente de acusação . Jus Navigandi, Teresina, ano 6, n. 54, fev. 2002. Disponível em: <http://jus2.uol.com.br/doutrina/texto.asp?id=2642>. Acesso em: 22 maio 2007

BITENCOURT, Cezar Roberto. Manual de Direito Penal - Parte Geral. $7^{\mathrm{a}}$ edição. São Paulo: Saraiva, 2002. pg. 21.

CANOTILHO, J.J. Direito Constitucional e Teoria da Constituição. Coimbra: Almedina, p. 1095.

CAPELA, Fábio Bergamin. Pseudo-evolução do Direito Penal . Jus Navigandi, Teresina, ano 6, n. 55, mar. 2002. Disponível em:

<http://jus2.uol.com.br/doutrina/texto.asp?id=2795>. Acesso em: 11 maio. 2007.

DORELLA, Paula Junqueira. Os direitos políticos nas Constituições brasileiras . Jus Navigandi, Teresina, ano 1, n. 19, set. 1997. Disponível em:

<http://jus2.uol.com.br/doutrina/texto.asp?id=1502>. Acesso em: 02 set. 2006.

DUARTE, Maércio Falcão. Evolução histórica do Direito Penal . Jus Navigandi, Teresina, ano 3, n. 34, ago. 1999. Disponível em:

<http://jus2.uol.com.br/doutrina/texto.asp?id=932>. Acesso em: 10 maio. 2007.

FERNANDES, Antônio Scarance. O papel da vítima no processo criminal. São Paulo: Malheiros, 1995. Pg. 132.

FERRAJOLI, Luigi. Direito e Razão. Editora Revista dos Tribunais: São Paulo. Tradução de Ana Paula Zomer Sua, Fauzi Hassan Choukr, Juarez Tavares e Luiz Flávio Gomes.

GERBER, Daniel. A apelação e o assistente do Ministério Público: um amor não correspondido. Jus Navigandi, Teresina, ano 9, n. 816, 27 set. 2005. Disponível em: <http://jus2.uol.com.br/doutrina/texto.asp?id=7336>. Acesso em: 22 maio 2007. 
LOPES JR, Aury. Sistemas de investigação preliminar no processo penal. Rio de Janeiro: Lúmen Júris, 2006. pg. 216.

LOPES JR, Aury. Introdução crítica ao processo penal (Fundamentos da instrumentalidade constitucional) Rio de Janeiro: Lúmen Júris, 2006. pg. 278.

MICHEL. Elementos de direito constitucional. São Paulo: Malheiros, 9. a ed., 1992.. Disponível em: <http://jus2.uol.com.br/doutrina/texto.asp?id=3618>. Acesso em: 02 jun. 2007.

NASSIF, Aramis. Júri - instrumento da soberania popular. Porto Alegre: Livraria do advogado, 1996, pg. 101.

NUCCI, Guilherme de Souza. Código de processo penal comentado. São Paulo: Editora Revista dos Tribunais, 2006. pg. 138/139

OLIVEIRA, José Aparecido Fausto de. Da não-recepção do art. 408, caput, do Código de Processo Penal . Jus Navigandi, Teresina, ano 7, n. 61, jan. 2003, citando TEMER,

PATENTE, Antônio Francisco. O assistente da acusação. Belo Horizonte : Del Rey, 2003

STRECK, Lênio Luiz. Tribunal do Júri: Símbolos e Rituais. Porto Alegre: Livraria do advogado, 2001. Pg. 159.

ZIYADE, Fátima. O assistente da acusação. Porto Alegre: Livraria do advogado. 